\title{
RAILROAD TIE RESPONSES TO DIRECTLY APPLIED RAIL SEAT LOADING IN BALLASTED TRACKS: A COMPUTATIONAL STUDY
}

\author{
Hailing Yu and David Jeong \\ Structures and Dynamics Division \\ John A. Volpe National Transportation Systems Center \\ Research and Innovative Technology Administration \\ U.S. Department of Transportation \\ Cambridge, MA 02142, U.S.A.
}

\section{ABSTRACT}

This paper describes work in-progress that applies the finite element (FE) method in predicting the responses of individual railroad crossties to rail seat pressure loading in a ballasted track. Both wood and prestressed concrete crossties are examined. The concrete tie is modeled as a heterogeneous medium with prestressing wires or strands embedded in a concrete matrix. The constitutive relations employed in the models are: elasticity followed by damaged plasticity for the concrete material, linear elastic bond-slip relations with potential initiation and evolution of damage to the bond for the steel-concrete interfaces, orthotropic elasticity followed by failure dictated by orthotropic stress criteria for the wood ties, extended Drucker-Prager plasticity for the granular and frictional ballast material, and elastic half space for the subgrade. The corresponding material parameters are obtained from the open literature.

Under a simplified pressure load uniformly distributed over the rail seat area, the FE method predicts tensile cracking at the tie base below the rail seats of a concrete tie and compressive failure in the rail seats of a wood tie. The rail seat force-displacement relations are obtained from the simulations. The resultant rail seat forces at which tie failures occur are compared for concrete and wood ties.

The FE method appears to be a promising tool for studying the railroad tie behavior under rail seat loading conditions in a ballasted track. Experimental data will be sought to calibrate the material parameters and verify the modeling approach. Additional track components, particularly rails, rail pads and fasteners, will be incorporated in future modeling efforts. This detailed modeling approach may help to shed light on the rail seat deterioration failure mechanisms observed in some concrete ties.

\section{INTRODUCTION}

Ties are an integral part of a railroad track system which also includes rails, rail pads, insulators, fasteners and ballast. The main functions of a railroad tie include supporting the rails and transferring rail forces to the ballast bed, maintaining track gauge and rail inclination, and insulating the rails electrically. Because of the relatively short service lives of timber ties, alternative tie materials such as concrete, steel and plastic composites have been employed or explored. In particular, concrete ties can be engineered to meet specific service requirements and add overall stability and performance to a railroad track structure. They were estimated to last twice as long as timber ties with the potential of lowered life cycle costs. These favorable qualities led to great interests and the first major installation of prestressed concrete ties in North America in 1966 [1]. Figure 1 illustrates the dual block (or two block, twin block, Figure 1a) as well as the more widely used monoblock concrete crossties (Figure 1b).

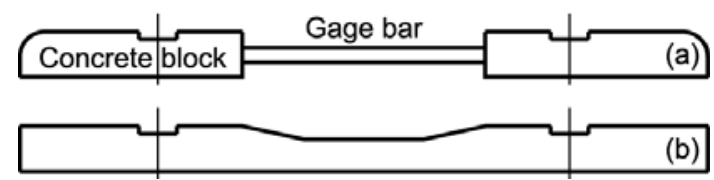

Figure 1: Illustration of concrete crossties: (a) dual block and (b) monoblock (reproduced from [1])

Despite the stated advantages, concrete ties account for only about five percent of the ties in track in North America [2]. 
There have been concerns over unresolved performance issues of concrete ties that can lead to increased maintenance costs and shortened service lives. One of the concerns is the susceptibility of concrete ties to rail seat deterioration (RSD), a failure mode identified as being most critical in a North American survey of railroad and transit authorities [2]. In an Amtrak passenger train derailment accident in Home Valley, Washington in 2005, significant rail seat abrasion (i.e., one of several possible causes of RSD failures) was observed on concrete crossties and believed to be the probable cause of the accident [3].

To meet the full potential of concrete ties in high speed and heavy haul services, a better understanding of their behavior under dynamic loading is needed. The design wheel load of a tie can be calculated from the static wheel load adjusted by such factors as load distribution among adjacent ties, dynamic forces and rail pad attenuation [4]. Dynamic forces may result from irregularities on wheel and rail surfaces, including wheel flats, worn wheel profiles, rail corrugations and rail joints. Both the magnitudes and the resonating frequency components of dynamic loads can lead to premature cracks in concrete ties [5]. In-situ data such as forces and deflections have been obtained from instrumented active track lines to better understand the loading environment that concrete ties are subjected to, and static and dynamic tests have also been conducted on individual ties to obtain basic performance data.

Moreover, computational models have been increasingly employed as an inexpensive and flexible tool to study concrete tie behavior. Such models have generally adopted two scales. The global track models often include rails, pads, ties, ballast and subgrade, which are treated as homogenized media. A global track model typically covers the domain of about ten ties. It may be subjected to static or dynamic loading conditions or coupled with vehicle models [e.g., 6-9]. However, concrete crossties consist of prestressing strands embedded in a concrete matrix, and the component interactions may contribute substantially to the overall behavior of individual ties. This calls for smaller scale models that account for the heterogeneity of concrete ties. Models at this scale involve explicit representations of the strand and the concrete components [10] as well as their interfaces governed by bondslip relationships $[11,12]$.

The objective of this research is to develop small scale, detailed finite element (FE) models for railroad concrete crossties and study the responses of individual ties to rail seat loading. The pretension release phase of the concrete tie manufacturing process is first simulated, and the resulting stress state serves as an initial condition as a concrete tie model is further subjected to rail seat loads. Currently rail fasteners, rail pads and rails are not modeled, and the rail seat force is applied as a pressure load uniformly distributed over the rail seats. The ballast and the subgrade are simulated with their respective geometric and constitutive characteristics. A wood tie model is also developed and subjected to the same type of rail seat loads.
The performances are then compared for wood and concrete crossties based on the FEA simulations.

\section{CONSTITUTIVE RELATIONS}

The commercial FE analysis software ABAQUS is employed in this study [13]. The constitutive relations of steel, concrete, concrete-strand interface, wood, ballast and subgrade are needed in modeling and discussed in this section.

\section{Steel}

The prestressing steel is assumed to be linear elastic with a perfectly plastic yield strength. The Young's modulus is $30,000,000$ psi $(206,843 \mathrm{MPa})$ and the Poison's ratio is 0.3 . The steel material for the rail is assumed to be linear elastic with the same Young's modulus and Poisson's ratio.

\section{Concrete}

A damaged plasticity model is available for the concrete material. Concrete behaves differently in tension and in compression as illustrated by the stress-strain curves in uniaxial tension and compression, respectively, in Figure 2. In uniaxial tension, linear elasticity is followed by tension stiffening (Figure 2a), and in uniaxial compression, linear elasticity is followed first by strain hardening and then by strain softening (Figure 2b). The compressive strength $\sigma_{\mathrm{cu}}$ is often one order of magnitude higher than the tensile strength $\sigma_{\mathrm{t} 0}$.

For linear elasticity, the stress-strain $\left(\sigma_{\mathrm{t}}-\mathcal{E}_{\mathrm{t}}\right.$ for tension and $\sigma_{\mathrm{c}}-\varepsilon_{\mathrm{c}}$ for compression) relations for uniaxial stresses may be expressed as

$$
\begin{aligned}
& \sigma_{\mathrm{t}}=E_{0} \varepsilon_{\mathrm{t}}, \varepsilon_{\mathrm{t}} \leq \sigma_{\mathrm{t} 0} / E_{0} \\
& \sigma_{\mathrm{c}}=E_{0} \varepsilon_{\mathrm{c}}, \varepsilon_{\mathrm{c}} \leq \sigma_{\mathrm{c} 0} / E_{0}
\end{aligned}
$$

where $E_{0}$ is the initial Young's modulus and $\sigma_{\mathrm{c} 0}$ is the elastic or proportional limit in uniaxial compression.

For tension stiffening in uniaxial tension, a stressdisplacement $\left(\sigma_{\mathrm{t}}-w_{\mathrm{t}}\right)$ relation is adopted and expressed in a form modified from the exponential equation proposed in [14]

$\sigma_{\mathrm{t}}=\sigma_{\mathrm{t} 0} e^{-a w_{\mathrm{t}} / w_{\mathrm{t} 0}}, \varepsilon_{\mathrm{t}}>\sigma_{\mathrm{t} 0} / E_{0}$

where $a$ and $w_{t 0}$ are constants to be determined. Apparently $\sigma_{\mathrm{t}}$ approaches 0 as $w_{\mathrm{t}} \rightarrow \infty$. If we assume that $w_{\mathrm{t} 0}$ corresponds to a sufficiently small $\sigma_{\text {tmin }}$ such that

$\left.\sigma_{\mathrm{t}}\right|_{w_{\mathrm{t}}=w_{\mathrm{t} 0}}=\sigma_{\mathrm{tmin}}$

and that the area under the $\sigma_{\mathrm{t}}-w_{\mathrm{t}}$ curve up to $w_{\mathrm{t}}=w_{\mathrm{t} 0}$ is equal approximately to the fracture energy $G_{\mathrm{f}}$ needed to create a unit area of cracked surface [15] 

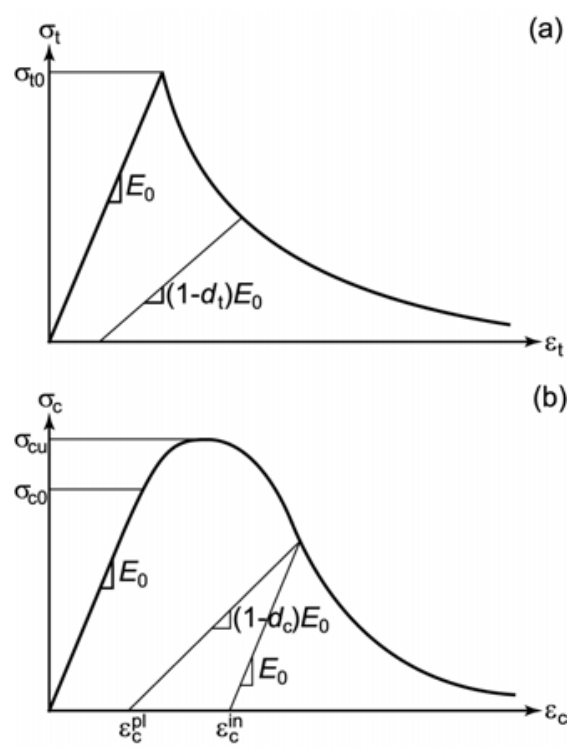

Figure 2: Concrete stress-strain responses to (a) uniaxial tension $\left(\sigma_{\mathrm{t}}-\varepsilon_{\mathrm{t}}\right)$ and $(\mathrm{b})$ uniaxial compression $\left(\sigma_{\mathrm{c}}-\varepsilon_{\mathrm{c}}\right)$

$\int_{0}^{w_{10}} \sigma_{\mathrm{t}} d w_{\mathrm{t}}=G_{\mathrm{f}}$

then $a$ and $w_{\mathrm{t} 0}$ can be solved from Eqs. (2-4) as

$a=\operatorname{Ln}\left(\sigma_{\mathrm{t} 0} / \sigma_{\mathrm{tmin}}\right)$

$w_{\mathrm{t} 0}=\frac{G_{\mathrm{f}} \operatorname{Ln}\left(\sigma_{\mathrm{t} 0} / \sigma_{\mathrm{tmin}}\right)}{\sigma_{\mathrm{t} 0}\left(1-\sigma_{\mathrm{tmin}} / \sigma_{\mathrm{t} 0}\right)}$

The equation for the strain hardening in uniaxial compression is modified from the work referenced in [16-18] and expressed as

$\sigma_{\mathrm{c}}=\sigma_{\mathrm{c} 0}+\frac{E_{0} \varepsilon_{\mathrm{c}}-\sigma_{\mathrm{c} 0}}{1+A\left(\frac{E_{0} \varepsilon_{\mathrm{c}}-\sigma_{\mathrm{c} 0}}{E_{0} \varepsilon_{\mathrm{c} 0}-\sigma_{\mathrm{c} 0}}\right)^{n}}, \frac{\sigma_{\mathrm{c} 0}}{E_{0}}<\varepsilon_{\mathrm{c}} \leq \varepsilon_{\mathrm{c} 0}$

where $A$ and $n$ are constants to be determined and $\varepsilon_{\mathrm{c} 0}$ is the strain corresponding to the maximum stress $\sigma_{\mathrm{cu}}$

$\left.\sigma_{\mathrm{c}}\right|_{\varepsilon_{\mathrm{c}}=\varepsilon_{\mathrm{c} 0}}=\sigma_{\mathrm{cu}}$

The derivative of the hardening curve is further assumed to reach zero at the peak stress

$\left.\frac{d \sigma_{\mathrm{c}}}{d \varepsilon_{\mathrm{c}}}\right|_{\varepsilon_{\mathrm{c}}=\varepsilon_{\mathrm{c} 0}}=0$
Solving Eqs. (7-9) yields the hardening constants as follows

$$
\begin{aligned}
& A=\frac{E_{0} \varepsilon_{\mathrm{c} 0}-\sigma_{\mathrm{c} 0}}{\sigma_{\mathrm{cu}}-\sigma_{\mathrm{c} 0}}-1 \\
& n=1+\frac{1}{A}=\frac{E_{0} \varepsilon_{\mathrm{c} 0}-\sigma_{\mathrm{c} 0}}{E_{0} \varepsilon_{\mathrm{c} 0}-\sigma_{\mathrm{cu}}}
\end{aligned}
$$

Last, the strain softening behavior is assumed to follow the empirical equation proposed in [18] and referenced in [19]

$\sigma_{\mathrm{c}}=\frac{\sigma_{\mathrm{cu}} r \varepsilon_{\mathrm{c}} / \varepsilon_{\mathrm{c} 0}}{r-1+\left(\varepsilon_{\mathrm{c}} / \varepsilon_{\mathrm{c} 0}\right)^{k r}}, \varepsilon_{\mathrm{c}}>\varepsilon_{\mathrm{c} 0}$

where $r$ and $k$ are empirical constants that can be calculated as

$$
\begin{aligned}
& r=0.8+\sigma_{\text {cu }} / 17 \\
& k=0.67+\sigma_{\text {cu }} / 62
\end{aligned}
$$

in which $\sigma_{\mathrm{cu}}$ is expressed in MPa.

At the tension stiffening or strain softening stages, concrete will unload according not to $E_{0}$ but to a degraded Young's modulus $E$. The tensile damage variable $d_{\mathrm{t}}$ and the compressive damage variable $d_{\mathrm{c}}$ are then introduced to define the degraded modulus in each case. The damage variable $d_{\mathrm{t}}$ in the uniaxial case may be defined according to Eq. (2) as

$d_{\mathrm{t}}\left(w_{\mathrm{t}}\right)=1-e^{-a w_{\mathrm{t}} / w_{\mathrm{t} 0}}$

In uniaxial compression, the relationship between the plastic strain $\varepsilon_{\mathrm{c}}^{\mathrm{pl}}$ and the inelastic strain $\varepsilon_{\mathrm{c}}^{\text {in }}$ (Figure 2b) is expressed as

$\varepsilon_{\mathrm{c}}^{\mathrm{pl}}=\varepsilon_{\mathrm{c}}^{\mathrm{in}}-\frac{d_{\mathrm{c}}}{1-d_{\mathrm{c}}} \frac{\sigma_{\mathrm{c}}}{E_{0}}$

where $\varepsilon_{\mathrm{c}}^{\mathrm{pl}}$ may assume the empirical form suggested in [20]

$\varepsilon_{\mathrm{c}}^{\mathrm{pl}}=0.166 \frac{\varepsilon_{\mathrm{c}}^{2}}{\varepsilon_{\mathrm{c} 0}}+0.132 \varepsilon_{\mathrm{c}}$

The damage variable $d_{\mathrm{c}}$ can then be calculated from Eqs. (12, 16-17) with any given $\varepsilon_{\mathrm{c}}$.

An overall stiffness degradation variable $d$ is further defined as a function of both $d_{t}$ and $d_{c}$, and it indicates the damaged state of a material integration point ( 0 : undamaged; 1 : completely damaged). In addition to uniaxial relations, biaxial and triaxial behaviors are similarly defined. This damaged plasticity modeling for concrete is based on the original work 
by Lubliner et al. [21], which was further extended by Lee and Fenves [22] to account for the behavior under cyclic loads.

The concrete model parameters used in this study are summarized in Table 1 for $\sigma_{\mathrm{cu}}=7,000 \mathrm{psi}(48.26 \mathrm{MPa})$. It is assumed that $\sigma_{\mathrm{t} 0}=0.085 \sigma_{\mathrm{cu}}, \sigma_{\mathrm{tmin}}=0.01 \sigma_{\mathrm{t} 0}$ and $\sigma_{\mathrm{c} 0}=0.6 \sigma_{\mathrm{cu}}$, based on the general literature on concrete properties and especially $[14,22]$. The non-derived parameters in Table $1\left(G_{\mathrm{f}}\right.$ and $\left.\varepsilon_{\mathrm{c} 0}\right)$ are those of concrete specimens with an average uniaxial compressive strength of 6,364 psi (43.88 MPa) in [14].

Table 1: Concrete model parameters

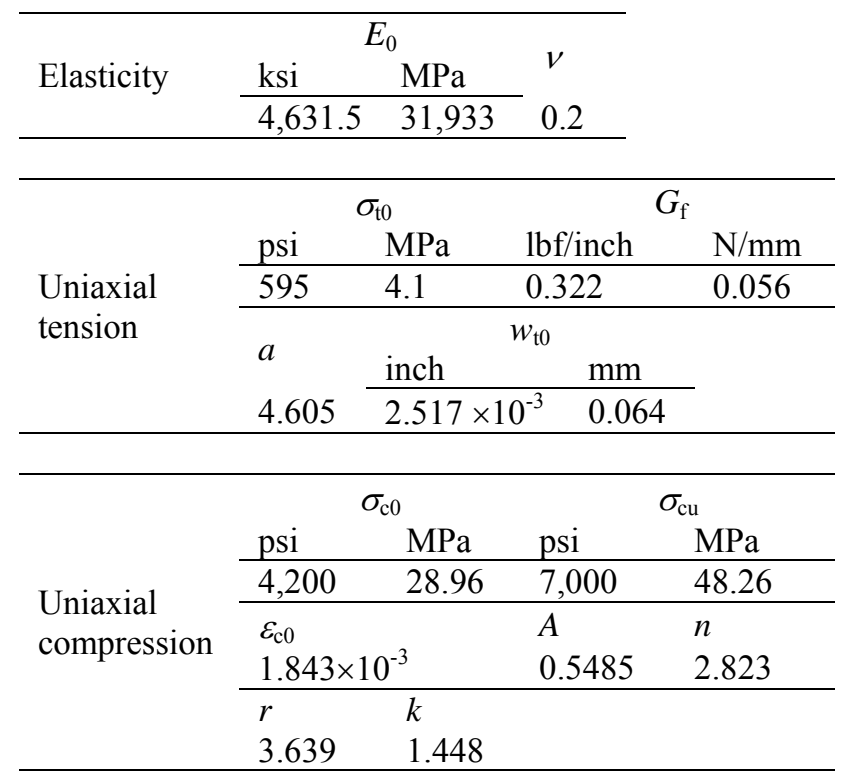

\section{Concrete-Strand Interfaces}

Cohesive elements are used to model the concrete-strand or concrete-wire interfaces. Figure 3 illustrates a cohesive element with a negligible thickness. It has a local coordinate system where $n$ is the normal direction and $s$ and $t$ are the shear directions. The corresponding traction components are $t_{\mathrm{n}}, t_{\mathrm{s}}$ and $t_{\mathrm{t}}$, respectively. Traction-displacement constitutive relations are adopted for the cohesive elements to model the interface behavior, that is, linear elasticity followed by damage initiation and evolution. There are four damage initiation criteria available: maximum nominal stress and strain criteria and quadratic nominal stress and strain criteria. For instance, the quadratic nominal stress criterion is stated as

$\left\{\frac{\left\langle t_{\mathrm{n}}\right\rangle}{t_{\mathrm{n}}^{0}}\right\}^{2}+\left\{\frac{t_{\mathrm{s}}}{t_{\mathrm{s}}^{0}}\right\}^{2}+\left\{\frac{t_{\mathrm{t}}}{t_{\mathrm{t}}^{0}}\right\}^{2}=1$

where $\langle\cdot\rangle$ is the Macaulay bracket, and $t_{\mathrm{n}}^{0}, t_{\mathrm{s}}^{0}$ and $t_{\mathrm{t}}^{0}$ are the nominal normal and shear strengths, respectively, for the interface. Damage evolution can be displacement or energy based. We currently employ a displacement based exponential softening law.

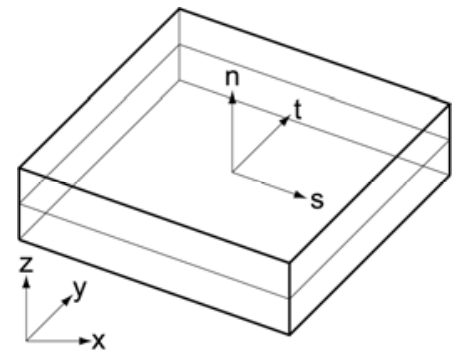

Figure 3: Illustration of a cohesive element [13]

The parameters needed for the interface modeling of concrete ties are the elastic stiffness $K$, the bond strength $\tau_{0}$ (for the shear strengths) and the failure displacement $u_{0}$. With the lack of more appropriate data, the normal strength is assumed to be the same as the shear strength; this appears acceptable as the interfaces are unlikely to fail in the normal direction for the concrete tie applications. While there have been numerous references characterizing the bond-slip relations between concrete and its reinforcing bars, tendons or strands, there has been far less research on the bond properties of prestressing strands or wires with concrete in railroad ties. The average flexural bond strength obtained by Abrishami and Mitchell [23] for smooth seven-wire strands with a nominal 0.375 inch $(9.525$ $\mathrm{mm}$ ) diameter is adopted. The same bond strength is assumed for the dented seven-wire strands or smooth single wires in this study; it is understood that this may not be accurate (see e.g, [25]) and that additional experimental study is merited to provide sufficient bond strength data for concrete ties. The current interface model parameters are $K=24,000 \mathrm{lbf} / \mathrm{inch}$ $(4,203 \mathrm{~N} / \mathrm{mm}), \tau_{0}=701 \mathrm{psi}(4.83 \mathrm{MPa})$ and $u_{0}=2$ inches $(50.8$ $\mathrm{mm})$.

\section{Wood}

Wood is often characterized as an orthotropic material with which three perpendicular axes are attached: the longitudinal axis $L$ parallel to the fiber (grain), the radial axis $R$ normal to the growth rings, and the tangential axis $T$ perpendicular to the fiber and tangent to the growth rings [24]. Twelve constants (nine of which are independent) may be used to define orthotropic elasticity: three moduli of elasticity $E$, three shear moduli $G$ and six Poisson's ratios $v$. The Poisson's ratio $v_{i j}(i \neq j i, j=L, R, T)$ has the physical interpretation of the transverse strain in the $j$-direction when the material is stressed in the $i$-direction. In general, $v_{i j}$ and $v_{j i}$ are not the same, and they are related by the following relation

$\frac{v_{i j}}{E_{i}}=\frac{v_{j i}}{E_{j}}$

The elastic constants define the elastic compliance according to the following equations 


$$
\left\{\begin{array}{c}
\varepsilon_{L L} \\
\varepsilon_{R R} \\
\varepsilon_{T T} \\
\gamma_{L R} \\
\gamma_{L T} \\
\gamma_{R T}
\end{array}\right\}=\left[\begin{array}{cccccc}
\frac{1}{E_{L}} & \frac{-v_{R L}}{E_{R}} & \frac{-v_{T L}}{E_{T}} & 0 & 0 & 0 \\
\frac{-v_{L R}}{E_{L}} & \frac{1}{E_{R}} & \frac{-v_{T R}}{E_{T}} & 0 & 0 & 0 \\
\frac{-v_{L T}}{E_{L}} & \frac{-v_{R T}}{E_{R}} & \frac{1}{E_{T}} & 0 & 0 & 0 \\
0 & 0 & 0 & \frac{1}{G_{L R}} & 0 & 0 \\
0 & 0 & 0 & 0 & \frac{1}{G_{L T}} & 0 \\
0 & 0 & 0 & 0 & 0 & \frac{1}{G_{R T}}
\end{array}\right]\left\{\begin{array}{c}
\sigma_{L L} \\
\sigma_{R R} \\
\sigma_{T T} \\
\sigma_{L R} \\
\sigma_{L T} \\
\sigma_{R T}
\end{array}\right\}
$$

Further, tensile, compressive and shear strengths for an orthotropic wood material can be denoted as follows

Table 2: Orthotropic strength limits

\begin{tabular}{|l|l|}
\hline Symbol & \multicolumn{1}{c|}{ Description } \\
\hline$X_{L t}$ & Tensile strength in the fiber direction $L$ \\
\hline$X_{L c}$ & Compressive strength in the fiber direction $L$ \\
\hline$X_{R t}$ & Tensile strength in the radial direction $R$ \\
\hline$X_{R c}$ & Compressive strength in the radial direction $R$ \\
\hline$X_{T t}$ & Tensile strength in the tangential direction $T$ \\
\hline$X_{T c}$ & Compressive strength in the tangential direction $T$ \\
\hline$S_{L R}$ & Shear strength in the $L-R$ plane \\
\hline$S_{L T}$ & Shear strength in the $L-T$ plane \\
\hline$S_{R T}$ & Shear strength in the $R-T$ plane \\
\hline
\end{tabular}

The current modeling approach determines that if any of the strength quantities are reached in their corresponding material directions, the material is considered failed.

The material properties of the white oak species in the wood handbook [24] were employed in the current study and summarized in Table 3.

Table 3: Wood material parameters based on the white oak species [24]

\begin{tabular}{|l|l|l|}
\hline$E_{L}(\mathrm{psi})$ & $E_{R}(\mathrm{psi})$ & $E_{T}(\mathrm{psi})$ \\
\hline $1,958,000$ & 319,154 & 140,976 \\
\hline$v_{L R}$ & $v_{L T}$ & $v_{R T}$ \\
\hline 0.369 & 0.428 & 0.618 \\
\hline$G_{L R}(\mathrm{psi})$ & $G_{L T}(\mathrm{psi})$ & $G_{R T}(\mathrm{psi})$ \\
\hline 168,388 & 158,598 & 41,118 \\
\hline
\end{tabular}

\begin{tabular}{|l|l|l|l|l|}
\hline$X_{L t}$ (psi) & $X_{L c}(\mathrm{psi})$ & $\begin{array}{l}X_{R t}, X_{T t} \\
(\mathrm{psi})\end{array}$ & $\begin{array}{l}X_{R c}, X_{T c} \\
(\mathrm{psi})\end{array}$ & $\begin{array}{l}S_{L R}, S_{L T} \\
(\mathrm{psi})\end{array}$ \\
\hline 15,200 & 7,440 & 800 & 1,070 & 2,000 \\
\hline
\end{tabular}

\section{Ballast and Subgrade}

The Extended Drucker-Prager model is applied to the ballast material. It is a plasticity model suitable for simulating granular, frictional materials. The main parameters used are Young's modulus (30,168 psi or $208 \mathrm{MPa})$, Poisson's ratio (0.3) and yield strength $(58 \mathrm{psi}$ or $400 \mathrm{KPa})$. A quick parameter study by increasing the yield strength to $100 \mathrm{psi}$ (or $689.5 \mathrm{KPa}$ ) shows only small differences in the predicted tie response. Similar modeling work for railroad ballast can be found in [26].

The subgrade is modeled as an elastic half space with a Young's modulus $72,519 \mathrm{psi}(500 \mathrm{MPa})$ and a Poisson's ratio 0.25 [27].

\section{FINITE ELEMENT MODEL}

The macroscopic heterogeneity of a concrete crosstie is modeled as shown in Figure 4. The geometry of concrete, strands/wires and their interfaces are explicitly represented and assigned the respective constitutive relations described above. The schematic of a full model including ballast and subgrade is shown in Figure 5. With reference to a global track system, the $x$-axis corresponds to the longitudinal rail direction, $y$-axis to the vertical direction and $z$-axis to the transverse direction. The concrete tie may be replaced with the homogeneous and orthotropic wood tie model to study the wood tie behavior. The ballast and subgrade are modeled for a distance corresponding to one tie spacing along the longitudinal or $x$-direction. The subgrade is bounded by a hemicylindrical layer of infinite elements intended to simulate the infinite nature of the subgrade support. Infinite elements are assigned appropriately selected decay functions for their basic solution variables, and they are employed in conjunction with standard finite elements to model the far field [28]. The tie spacing is assumed to be 30 inches $(762 \mathrm{~mm})$ for concrete ties and 19 inches for wood ties, and the ballast depth is 24 inches $(609.6 \mathrm{~mm})$ in this study.

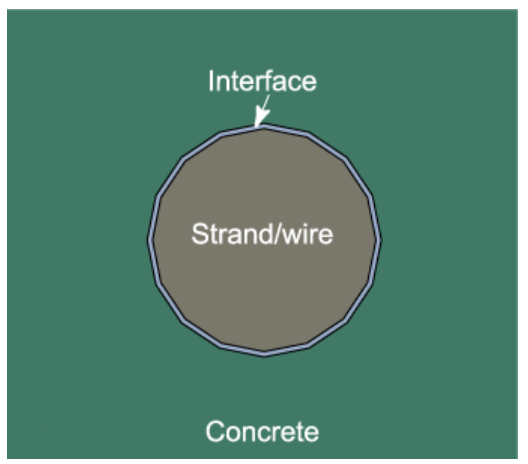

Figure 4: Macroscopic heterogeneity in concrete tie modeling: concrete, a strand/wire and their interface 


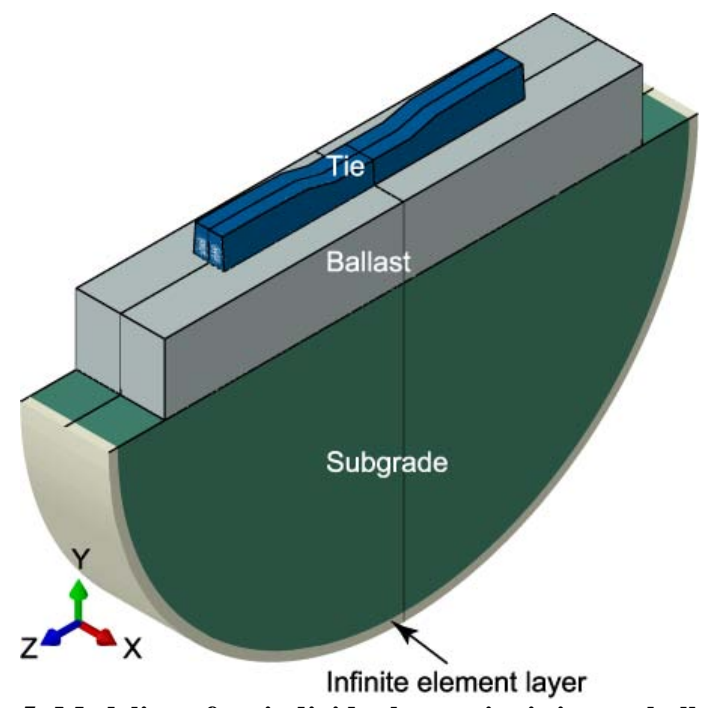

Figure 5: Modeling of an individual crosstie sitting on ballast and subgrade bounded by an infinite element layer

\section{Railroad Concrete Crossties}

Figure 6 shows the geometry of a typical concrete crosstie and the necessary parameters to describe the geometry. Two railroad concrete crossties are studied here, one with eight prestressing strands and the other with twenty four prestressing wires. The geometric parameters of these two ties are shown in Table 4.

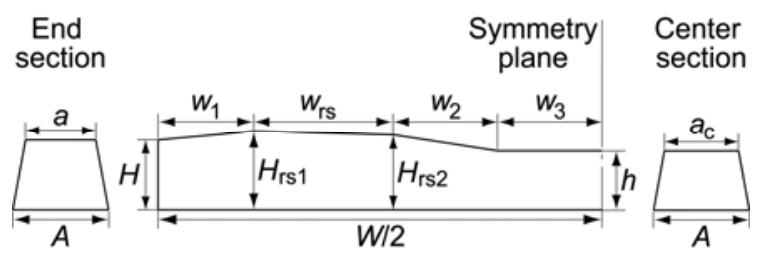

Figure 6: Geometry of a concrete crosstie

Table 4: Geometric parameters of the 8-strand and 24-wire ties

\begin{tabular}{|c|c|c|c|}
\hline & & 8 -strand tie & 24-wire tie \\
\hline \multirow{2}{*}{$a, a_{\mathrm{c}}, A$} & inch & $8.980,9.375,10.375$ & $8.998,9.375,10.375$ \\
\hline & $\mathrm{mm}$ & $228.1,238.1,263.5$ & $228.5,238.1,263.5$ \\
\hline \multirow{2}{*}{$\begin{array}{l}H, H_{\mathrm{rs} 1}, \\
H_{\mathrm{rs} 2}, h\end{array}$} & inch & $\begin{array}{l}9.938,9.825,9.425 \\
7.125\end{array}$ & $\begin{array}{l}9.813,9.825,9.425 \\
7.125\end{array}$ \\
\hline & $\mathrm{mm}$ & $\begin{array}{l}252.4,249.6,239.4, \\
181.0\end{array}$ & $\begin{array}{l}249.3,249.6,239.4 \\
181.0\end{array}$ \\
\hline \multirow{2}{*}{$\begin{array}{l}w_{1}, w_{\mathrm{rs}}, w_{2}, \\
w_{3}, W / 2\end{array}$} & inch & $\begin{array}{l}13.125,16,9, \\
12.875,51\end{array}$ & $\begin{array}{l}13.125,16,9, \\
12.875,51\end{array}$ \\
\hline & $\mathrm{mm}$ & $\begin{array}{l}333.4,406.4,228.6 \\
327.0,1295.4\end{array}$ & $\begin{array}{l}333.4,406.4,228.6 \\
327.0,1295.4\end{array}$ \\
\hline \multicolumn{2}{|l|}{ Rail seat cant } & $1: 40$ & $1: 40$ \\
\hline
\end{tabular}

Table 5 further shows the respective strand/wire properties of both ties. In addition to the given design data, the strand/wire volumes and interface areas are calculated and shown in italics in Table 5. Compared to the 8-strand tie, the 24-wire tie increases the bonding surface area by $65.6 \%$ while reducing the steel volume by $8.6 \%$. With assumed quarter symmetries in both the geometry and the loading, only one fourth of the schematic shown in Figure 5 is considered in FE modeling. Figure 7 shows the typical quarter symmetric FE meshes for the 8-strand and 24-wire concrete crossties.

Table 5: Strand/wire properties of the 8-strand and 24-wire ties

\begin{tabular}{llll}
\hline & & 8-strand tie & 24-wire tie \\
\hline Strand type & & Seven-wire, indented & Single wire \\
\hline \multirow{2}{*}{ Diameter } & inch & 0.375 & 0.207 \\
& $\mathrm{~mm}$ & 9.525 & 5.258 \\
\hline \multirow{2}{*}{ Volume } & inch $^{3}$ & 90.12 & 82.38 \\
& $\mathrm{~cm}^{3}$ & 1,477 & 1,350 \\
\hline \multirow{2}{*}{ Interface area } & $\mathrm{inch}^{2}$ & 961.3 & 1592 \\
& $\mathrm{~cm}^{2}$ & $6,201.9$ & 10,271 \\
\hline \multirow{2}{*}{ Pretension } & $\mathrm{lbf}$ & 17,210 & 6,550 \\
\multirow{2}{*}{ sorce per } & $\mathrm{N}$ & 76,554 & 29,136 \\
\hline \multirow{2}{*}{ Pretension } & $\mathrm{psi}$ & 155,822 & 194,630 \\
& $\mathrm{MPa}$ & 1,074 & 1,342 \\
\hline \multirow{2}{*}{ Strength } & $\mathrm{psi}$ & 270,600 & 260,000 \\
& $\mathrm{MPa}$ & 1,866 & 1,793 \\
\hline
\end{tabular}

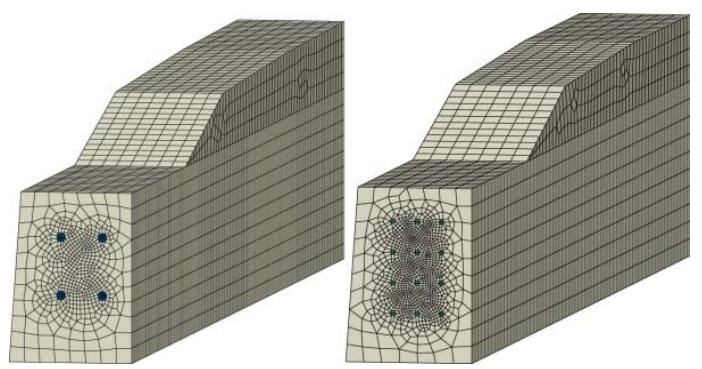

Figure 7: Typical quarter symmetric FE meshes for the 8-strand and 24-wire concrete crossties

\section{Railroad Wood Crosstie}

The wood tie is assumed to have the same length as those of the concrete ties (102 inches), a width of 9 inches and a depth of 7 inches. The material properties are assumed to follow those of the white oak species defined above. A steel plate is used to cover the rail seat area.

\section{Boundary, Initial and Loading Conditions}

Roller boundary conditions are applied on the symmetric planes to enforce the symmetric conditions. In addition, the ballast and subgrade models span a length equal to one tie spacing in the $x$ - or longitudinal rail direction, and their $y-z$ surfaces bounding the FE domains are also assigned roller boundary conditions to account for the infinite structures that continue along the $x$-direction.

The strands or wires are assigned the initial pretensions specified in Table 5. These prestresses are then released in the simulations to yield the initial stress and strain states in concrete ties before any additional loading may be applied. 
These simulations are conducted as a static analysis step. Further, as illustrated in Figure 8, uniformly distributed pressure loads are applied directly on predefined rail seat areas. The simulation of this loading scenario is conducted as a dynamic analysis step.

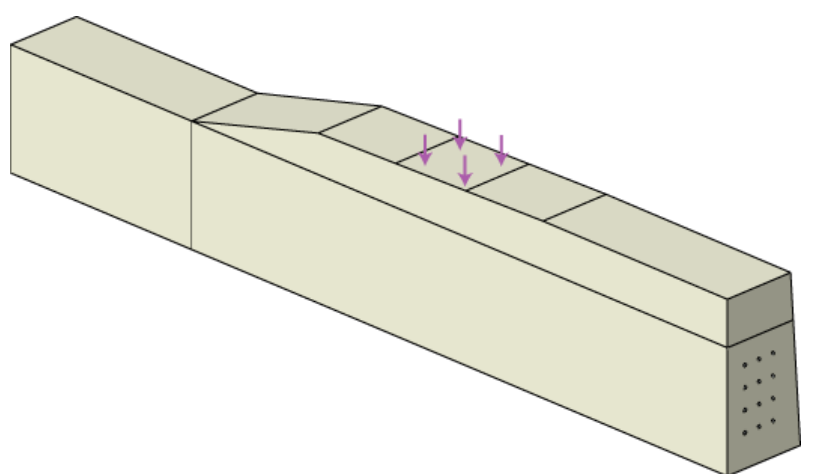

Figure 8: Illustration of uniformly distributed pressure loads applied directly on a predefined rail seat area

\section{Scope}

The FE models are used to study the behavior of individual railroad crossties supported by ballast and subgrade. The macroscopic heterogeneity and material nonlinearity of the concrete ties are considered, allowing the pretention released stress states to be determined from the simulations. Due to the omission of rail fasteners, a load transferring path from the rail to the tie is not sufficiently defined, thus making it difficult to apply more realistic dynamic vehicle-rail loads at this modeling stage. As a simplification, uniform rail seat pressures are applied instead.

The FE framework developed in this paper is applied in a comparative study of the railroad tie behavior under direct rail seat loading scenarios. We have not identified theoretical or experimental studies on the behavior of railroad ties under similar conditions and therefore, verification or validation of the current models is not conducted. Mesh sensitivities, if any, will be mainly attributed to the softening behavior of the concrete and the interface elements. However, for the purpose of this comparative study, it suffices to have comparable mesh sizes for the simulation results based on the computational tie models to be comparable.

\section{RESULTS}

The results obtained from the FE analyses of the pretension release phase are presented and compared for the 8strand and 24-wire ties. The FEA results of the rail seat loading cases are compared for both concrete ties and the wood tie.

\section{Pretension Release}

The initial axial tensile stresses prescribed for the strands/wires are the same as the data shown in Table 5. The initial pretension release is first simulated, and it results in tie deformations, some degree of interface deterioration toward the tie ends, compressive stress and strain states in the concrete and losses of pretensions in the strands/wires. Figure 9 shows the deformation profiles of the 8-stand and 24-wire crossties after pretension release. Figure 10 shows the contours of interface deterioration $D$, of which the main observations are: (1) the interfaces remain intact for most parts of the ties (bluish contours with $D=0$ ), (2) there are interface deteriorations toward the ends of the ties (greenish contours with $D>0$ ), and (3) interface deteriorations are more limited in extent for the 24-wire tie than for the 8-strand tie.

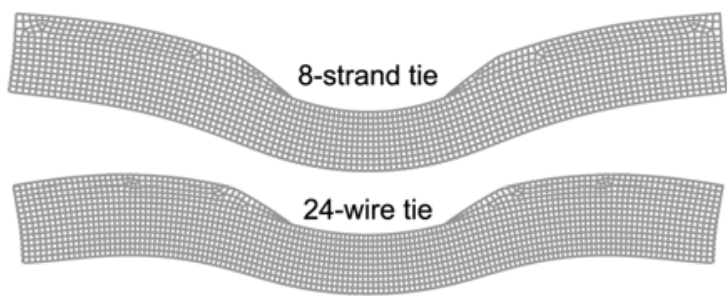

Deformation scale factor: 500

Figure 9: Predicted deformation profiles of the two concrete crossties upon pretension release

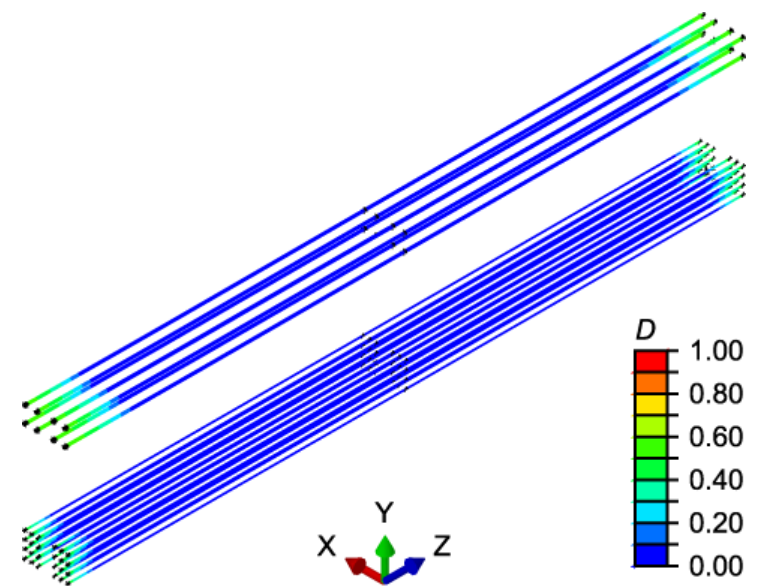

Figure 10: Predicted interface deterioration contours for the 8strand and 24-wire ties after pretension release

Figure 11 shows the contours of the minimum principal stress $\sigma_{\min }$ along the tie's longitudinal cross section at the center. The 24-wire tie displays a slightly stronger compressive stress state upon pretension release than the 8-strand tie. The residual tensions averaged for all strands/wires are plotted in Figure 12 as a function of the relative distance to the center of the tie. The residual tensions are compared with their initial pretensions in this plot. Figure 13 further plots the ratio of the residual tension to the pretension for both ties. Again the 24wire tie shows better retention of the pretension than the 8strand tie, and this is consistent with the fact that there is more interfacial area in the 24-wire tie for bonding with the concrete. 


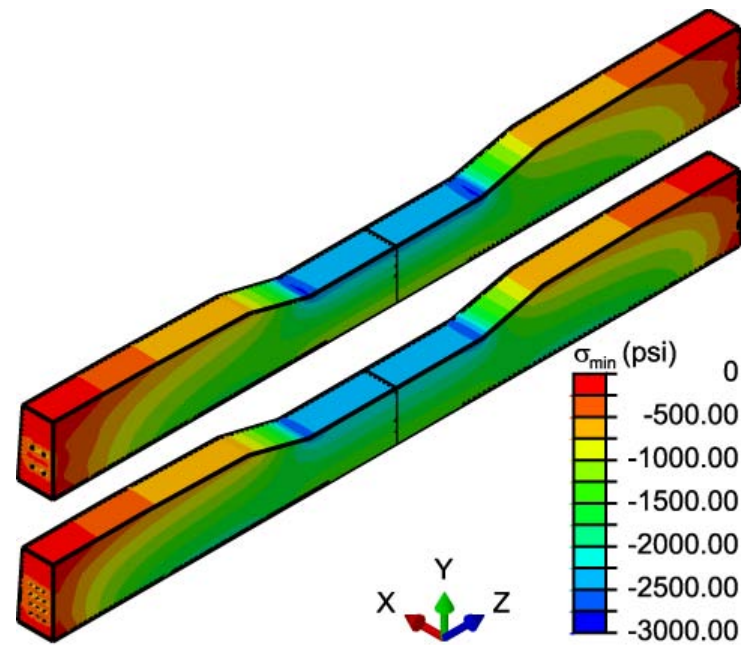

Figure 11: Predicted compressive stress state contours in concrete for the 8-strand and 24-wire ties after pretension release (1 psi = $6895 \mathrm{~Pa})$

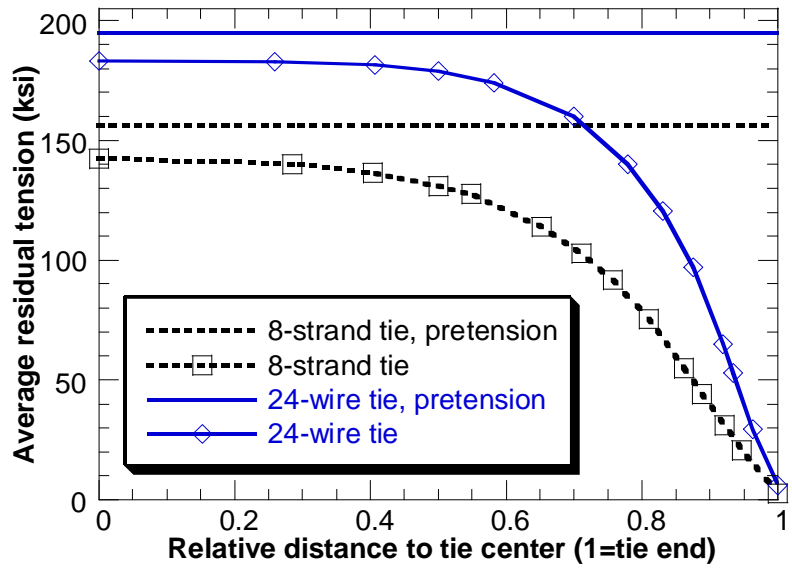

Figure 12: Predicted average residual tensions in the strands/wires as a function of the relative distance to the tie center $(1 \mathrm{ksi}=\mathbf{6 8 9 5}$ kPa)

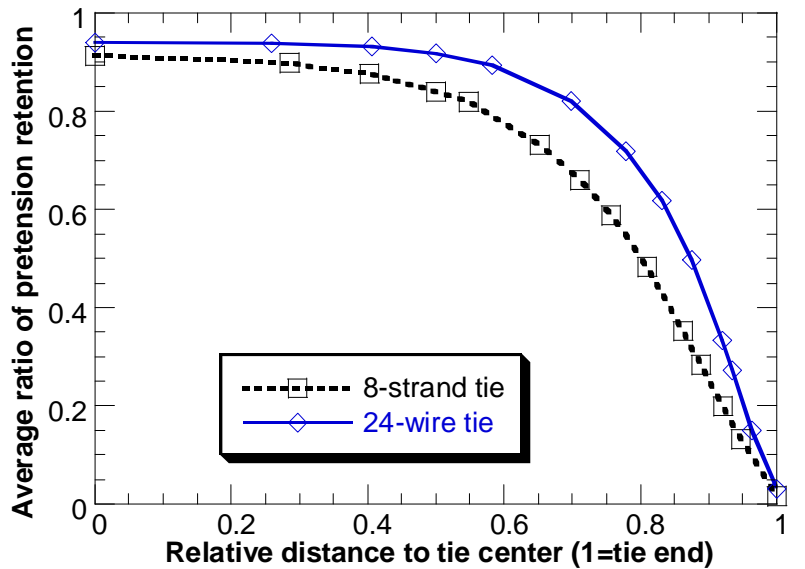

Figure 13: Predicted average ratios of retained pretensions as a function of the relative distance to the tie center
The data obtained from the simulations of the pretension release phase can also be used to calculate the transfer lengths of prestressing strands/wires. Experimentally the strand end slips or the compressive strains on the concrete surface can be measured and the transfer lengths calculated from these measured data (see e.g., [29-30]). The FE simulation method presented in this study can yield not only similar data to compare with the experimental results but also additional residual tension data for the strands/wires, which are difficult to measure in an experimental setting. The latter may yield more accurate predictions of the transfer lengths.

\section{Direct Rail Seat Loading}

As illustrated in Figure 8, a pressure load increasing linearly to $50 \mathrm{ksi}(344.7 \mathrm{MPa})$ in one second is applied on a predefined rail seat area of about $22.55 \mathrm{inch}^{2}\left(145.5 \mathrm{~cm}^{2}\right)$ for the concrete ties and 19.375 inch $^{2}$ for the wood tie. The duration of the load is randomly selected. Under this pressure loading, tensile damages at the bases of both the 8 -strand and the 24-wire concrete crossties are observed in the simulations. A concrete tie is considered damaged as the concrete tensile damage variable $d_{\mathrm{t}}$ reaches a substantial amount (greater than 0.1 ). On the other hand, compressive damage is observed on the rail seat of the wood tie as the compressive stress along the rail seat loading direction reaches its strength limit in that direction.

The vertical resultant forces acting on the rail seats are calculated for the quarter symmetric models and plotted in Figure 15(a) versus the corresponding displacements averaged over the predefined rail seat area. It is noted that the rail seat forces in this and subsequent plots account for only half of the typical railroad wheel loads. A rail seat displacement relative to the tie base is also calculated, and the resulting force-relative displacement relations are plotted in Figure 15(b) for the three ties. All curves are plotted up to the point of perceived tie failure as defined above. The 8-strand tie appears to be more susceptible to tensile cracking than the 24-wire tie, as evidenced by the lower rail seat force at failure (31.6 vs. 40.6 kips). As discussed, the wood tie fails with a different mechanism than that in the concrete ties; in addition, it presents a more compliant response overall and sustains a lower amount of rail seat force at failure (21.3 kips). 

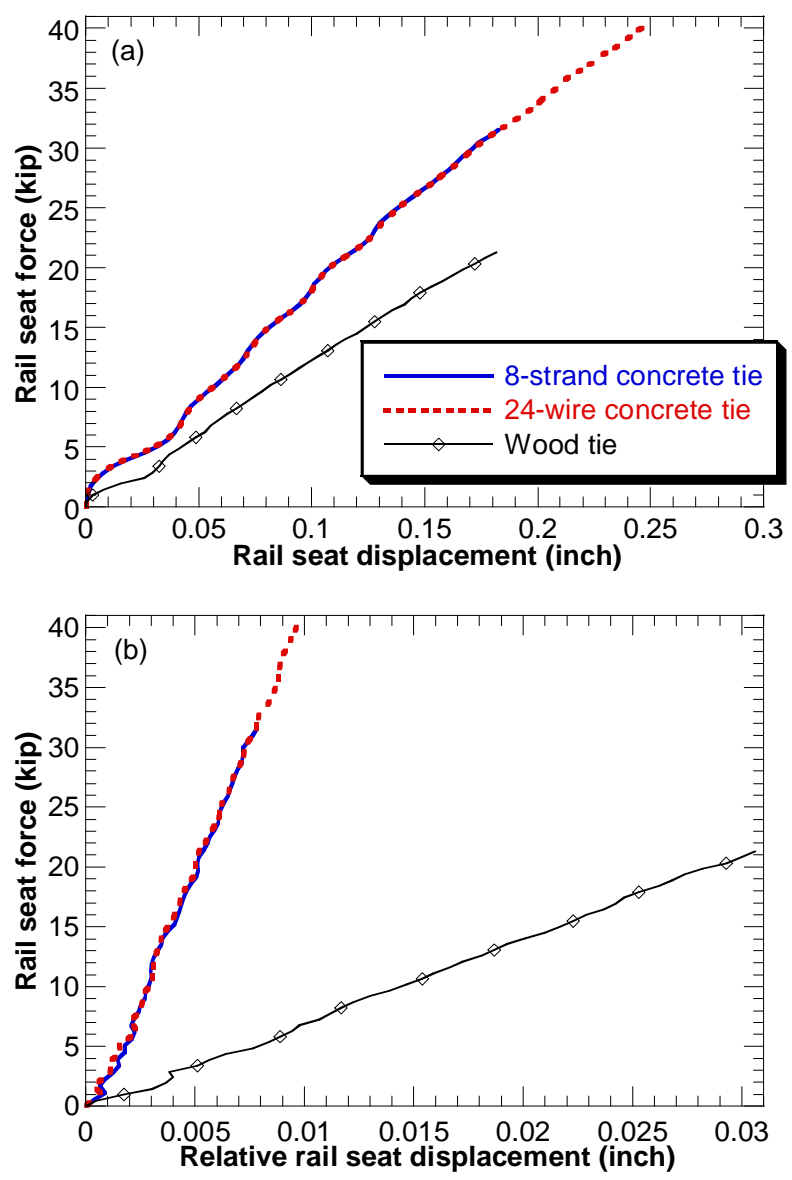

Figure 15: Rail seat force vs. (a) rail seat displacement and (b) rail seat displacement relative to tie base for the three railroad crossties (1 kip = $4.448 \mathrm{kN}, 1$ inch $=25.4 \mathrm{~mm})$

\section{CONCLUSIONS AND FUTURE WORK}

This paper presents an FE analysis framework for individual concrete crossties that takes into account their macroscopic heterogeneity and material nonlinearity. In particular, the interfaces between the steel reinforcements and the concrete matrix are explicitly modeled and assigned bondslip relationships. The FE method is able to predict the stress states in the two concrete ties with eight prestressing strands and twenty four prestressing wires, respectively, upon release of the pretensions in the reinforcing steel. The 24-wire tie shows better retention of the pretensions than the 8-strand tie, likely owing to the increased bonding surfaces between the wires and the concrete in the 24-wire tie.

A wood tie model following orthotropic elasticity and orthotropic stress failure criteria is also developed, and ballast and subgrade are included in modeling to provide support for the ties. Under a simplified rail seat pressure loading, both concrete ties appear to experience tensile cracking failure at the tie base, whereas the wood tie experiences compressive failure in the rail seat under sufficiently large rail seat forces. The 24wire concrete tie fails at a larger rail seat force than the 8-strand concrete tie. Both concrete ties sustain larger rail seat forces than what the wood tie does upon tie failure. The effect of subgrade modeling on the predicted damage states of concrete ties was discussed in a previous paper [12].

According to the analyses, a uniformly distributed rail seat pressure load does not lead to RSD failure in the concrete ties. In future work, the rail fastening system will be incorporated in the FE analysis framework in an attempt to simulate the complex stress states in the rail seats more accurately. In addition, bond strength data will be sought for different strand/wire diameters and surface conditions. The FE modeling approach will also need to be verified or validated with experimental results.

\section{ACKNOWLEDGEMENT}

The work described in this paper was sponsored by the Office of Research and Development, Federal Railroad Administration, U.S. Department of Transportation, under the direction of Mr. Gary Carr, Chief of the Track Research Division. Technical discussions with Mr. Michael Coltman, Dr. Ted Sussmann and Mr. John Choros are gratefully acknowledged.

\section{REFERENCES}

[1] A.N. Hanna, 1979: "State-of-the-art report on prestressed concrete ties for North American railroads," PCI Journal, September-October: 32-61.

[2] J.C., Zeman, J.R., Edwards, C.P.L. Barkan, and D.A. Lange, 2009: "Failure mode and effect analysis of concrete ties in North America," Proceedings of the 9th International Heavy Haul Conference, Shanghai, China.

[3] National Transportation Safety Board, 2006: Railroad accident brief. NTSB/RAB-06/03.

[4] S. Freudenstein and F. Haban, 2006: "Prestressed concrete sleepers," European Railway Review, Issue 4:73-79.

[5] M. Murray, and Z. Cai, 1998: "Prestressed concrete sleeper: Literature review," Report ARA Project Ref: 15250, Australasian Railway Association Inc.

[6] P.K., Woodward, B., Zettor, A., Kaddouri, and M., Banimahd, 2005: "Advanced non-linear dynamic finite element modeling of railway track behavior," Proceedings of the 8th International Conference on Railway Engineering, London.

[7] M., Banimahd, and P.K., Woodward, 2007: "Numerical study of train speed effect on railway track response," Proceedings of the 9th International Conference on Railway Engineering, London.

[8] M., Banimahd, and P.K., Woodward, 2007: "ThreeDimensional finite element modelling of railway transitions," Proceedings of the 9th International Conference on Railway Engineering, London.

[9] C. González-Nicieza, M.I. Álvarez-Fernández, A. Menéndez-Díaz, A.E. Álvarez-Vigil and F. AriznavarretaFernández, 2008: "Failure analysis of concrete sleepers in heavy haul railway tracks," Engineering Failure Analysis, Volume 15, Issues 1-2, Pages 90-117. 
[10] H. Yu, D.Y. Jeong, 2010: "Finite element modeling of railroad concrete crossties - a preliminary study," Proceedings of International Conference on Railway Engineering, Beijing, pp. 277-282.

[11] R., Gustavson, 2002: "Bond behavior of four types of strands in sleepers during release of prestress and loading," Chalmers University of Technology, Department of Structural Engineering, Report 02:14, Göteborg.

[12] H. Yu, D.Y. Jeong, J. Choros, and T. Sussmann, "Finite element modeling of prestressed concrete crossties with ballast and subgrade support," Proceedings of the ASME 2011 International Design Engineering Technical Conferences \& Computers and Information in Engineering Conference, August 29-31, 2011, Washington, DC, USA.

[13] Dassault Systèmes Simulia Corp. ABAQUS Analysis User's Manual.

[14] V.S. Gopalaratnam, S.P. Shah, 1985: "Softening response of plain concrete in direct tension," ACI Journal, Proceedings V. 82, No. 3, pp. 310-323.

[15] A. Hillerborg, M. Modeer, P.E. Petersson, 1976: “Analysis of crack formation and crack growth in concrete by means of fracture mechanics and finite elements," Cem. Concr. Res. 6, pp. 773-782.

[16] S. Popovics, 1970: "A review of stress-strain relationships for concrete," ACI Journal, Vol. 67, No. 14, pp. 243-248.

[17] E. Thorenfeldt, A. Tomaszewicz, J.J. Jensen, 1987: "Mechanical properties of high-strength concrete and application in design," Proceedings of the Symposium "Utilization of High Strength Concrete," Stavanger, Norway, pp. 149-159.

[18] M.P. Collins, Mitchell, D., 1991: Prestressed Concrete Structures, Prentice-Hall, New Jersey.

[19] M. Elmorsi, M. Reza Kianoush, and W.K. Tso, 1998: "Nonlinear analysis of cyclically loaded reinforced concrete structures," ACI Structural Journal, Vol. 95, No. S66, pp. 725-739.

[20] D. Palermo, F.J. Vecchio, 2003: "Compression field modeling of reinforced concrete subjected to reversed loading: formulation," ACI Structural Journal, Vol. 100, No. S64, pp. 616-625.
[21] Lubliner, J., Oliver, J., Oller, S. and Oñate, E. 1989. A plastic-damage model for concrete. International Journal of Solids and Structures. Vol. 25:299-329.

[22] Lee, J. and Fenves, G.L. 1998. Plastic-damage model for cyclic loading of concrete structures. Journal of Engineering Mechanics. Vol. 124, No. 8:892-900.

[23] H. Abrishami, D. Mitchell, 1993: "Bond characteristics of pretensioned strand," ACI Materials Journal, Vol. 90, No. 3, pp. 228-235.

[24] Bergman, R., Cai, Z., Carll, C.G., Clausen, C.A., Dietenberger, M.A., Falk, R.H., Frihart, C.R., Glass, S.V., Hunt, C.G., Ibach, R.E., Kretschmann, D.E., Rammer, D.R., Ross, R.J., Stark, N.M., Wacker, J.P., Wang, X., White, R.H., Wiedenhoeft A.C., Wiemann, M.C., Zelinka, S.L., Wood handbook - Wood as an engineering material. General Technical Report FPL-GTR-190. Madison, WI: U.S. Department of Agriculture, Forest Service, Forest Products Laboratory: 508 p. 2010.

[25] R. Gustavson, 2004: "Experimental studies of the bond response of three-wire strands and some influencing parameters," Materials and Structures, Vol. 37, No. 2, pp. 96-106.

[26] Indraratna, B., Salim, W. and Rujikiatkamjorn, C. 2007. Development and application of constitutive model for railway ballast. In: Yin, JH, Li, XS, Yeung, AT \& Desai, CS (eds.), International Workshop on Constitutive Modelling, Hong Kong, pp. 685-696.

[27] Q. Feng, X. Lei, S. Lian, 2010: "Ground vibration generated by high-speed train," Proceedings of International Conference on Railway Engineering, Beijing, pp. 379-384.

[28] Dassault Systèmes Simulia Corp. ABAQUS Theory Manual.

[29] B.H. Oh, E.S. Kim, 2000: "Realistic evaluation of transfer lengths in pretensioned, prestressed concrete members," ACI Structural Journal, Vol. 97, No. S83, pp. 821-830.

[30] J.R. Martí-Vargas, C.A. Arbeláez, P. Serna-Ros, and C. Castro-Bugallo, 2007: "Reliability of transfer length estimation from strand end slip," ACI Structural Journal, Vol. 104, No. S47, pp. 487-494. 